\title{
RUMO À PROSA: ASPECTOS DE UM NOVO PROJETO DE TRADUÇÃO DOS PETITS POÈMES EN PROSE, DE BAUDELAIRE
}

\author{
Eduardo Horta Nassif Veras \\ Universidade Federal do Triângulo Mineiro, Uberaba, Minas Gerais, Brasil
}

\begin{abstract}
Resumo: O artigo apresenta, em linhas gerais, as principais diretrizes que guiaram o trabalho de uma nova tradução dos Petits poèmes en prose, de Baudelaire, realizado por mim em parceria com Isadora Petry. Procuro mostrar, primeiramente, como o projeto do poeta francês de passagem para prosa demorou a ser compreendido mesmo pela crítica especializada, o que explica em grande parte o caráter poético das primeiras traduções brasileiras. Por outro lado, a radicalização do prosaísmo também não parece dar conta do desafio de traduzir essas "bagatelas laboriosas", concebidas por Baudelaire como uma experiência poética essencialmente ambivalente. Sempre em diálogo com a Crítica, nossa tradução procurou enfrentar esse desafio da ambivalência, do qual este artigo aborda dois aspectos: o encontro da prosa com a poesia e a apropriação irônica e significativa do lugar-comum.
\end{abstract}

Palavras-chaves: Poemas em prosa; Baudelaire; Le Spleen de Paris; Tradução.

\section{TOWARDS PROSE: ASPECTS OF A NEW TRANSLATION PROJECT OF PETITS POÈMES EN PROSE, BY BAUDELAIRE}

\begin{abstract}
The article presents, in general lines, the main guidelines that guided the work of a new translation of Petits poèmes en prose, by Baudelaire, carried out by me in partnership with Isadora Petry. I try to show, first, how the French poet's prose poetry project took a long transition time to be understood even by specialist critics, which explains,
\end{abstract}


in large part, the poetic character of the first Brazilian translations. On the other hand, the radicalization of prosaism also seems not to be able to deal with the challenge of translating these "laborious trifles", conceived by Baudelaire as an essentially ambivalent poetical experience. Always in dialogue with Literary Criticism, our translation sought to meet this challenge of ambivalence, from which this article addresses two aspects: the encounter of prose with poetry and the ironic and meaningful appropriation of the commonplace.

Keywords: Poems in prose; Baudelaire; Le Spleen of Paris; Translation.

Como na França, o surgimento de uma recepção crítica sistemática dos Petits poèmes en prose, de Baudelaire, é bastante tardia por aqui, especialmente se comparada com o caso de Les Fleurs du mal. Lá, aqueles poemas foram, incialmente, considerados como esboços abortados de poemas em verso, como uma espécie de queda no prosaísmo, conforme a apreciação de Suzanne Bernard, em seu célebre livro Le poème en prose de Baudelaire à nos jours (1959). Até meados dos anos setenta, menos de $1 \%$ dos trabalhos críticos dedicados à obra de Baudelaire tinham como objeto de estudo os poemas de Le Spleen de Paris, segundo a contagem de Claude Pichois. As primeiras leituras de fôlego só apareceram mais de um século depois da publicação póstuma dos poemas em prosa. Dentre elas, destaca-se o importante livro de Barbara Johnson Défigurations du langage poétique : la seconde révolution baudelairienne, publicado em 1979. Conforme sugere o subtítulo da obra, Johnson interpreta a passagem de Baudelaire para a prosa como uma revolução poética do mesmo quilate daquela realizada por ele nos poemas em verso de Fleurs $d u$ mal. Essa revolução corresponde ao processo de destruição crítica da linguagem figurativa, isto é, da própria linguagem poética tradicional, fundada sobre o primado do ritmo e da imagem. O estudo de Johnson mostra que a prosa de Baudelaire atenta contra a "ilusão poética" resultante do uso acrítico da metáfora e da fluência verbomusical. Em outras palavras, a crítica norte-americana tornou-se uma das primeiras leitoras a reconhecer a autonomia do projeto baudelairiano de passagem para a prosa e, sobretudo, a compreender o que ele contém de crítica e ruptura com a tradição lírica.

Cad. Trad., Florianópolis, v. 38, n $^{0}$ esp. Baudelaire 150 anos, p. 54-69, ago-dez, 2018 
Nos últimos anos, com o despertar do interesse pela prosa, como problema teórico e como norte da criação poética contemporânea, e com a publicação de diversos estudos de peso sobre o "último Baudelaire" e seus pequenos poemas em prosa, ficou claro que a recepção crítica e tradutória de Le Spleen de Paris, tanto na França como mundo afora, carecia de ferramentas teóricas para compreender o que estava em jogo na produção daquelas "bagatelas laboriosas" destinadas à publicação em jornais e revistas franceses dos mais diversos formatos. Baudelaire ressaltou, diversas vezes em sua correspondência, a dificuldade de realização daquela poesia essencialmente ambivalente, espremida entre a tradição lírica e sua ironização, entre a memória do verso e a realidade moderna da prosa, entre o ideal antigo e o spleen de Paris. Em uma carta a Sainte-Beuve, de 4 de maio de 1865 , ele deixa claro o quanto seu projeto era marcado por tamanha ambivalência que tornava sua realização bastante difícil:

\begin{abstract}
Ai de mim! os Poemas em prosa aos quais você ainda havia lançado um encorajamento recente estão muito atrasados. Eu me imponho sempre sobre os braços tarefas muito difíceis. Fazer cem bagatelas laboriosas que exigem um bom humor constante (bom humor necessário até para tratar de temas tristes), uma excitação bizarra que precisa de espetáculos, multidões, música, iluminação pública, eis o que eu quis fazer! Eu tenho apenas sessenta, e não consigo mais avançar. Preciso daquele famoso banho de multidão cuja incorreção lhe chocou com razão (BAUDELAIRE, 1973b, p. 493 , tradução minha). ${ }^{1}$
\end{abstract}

\footnotetext{
${ }^{1}$ Hélas! les Poèmes en prose, auxquels vous avez encore décoché un encouragement récent, sont bien attardés. Je me mets toujours sur les bras des besognes difficiles. Faire cent bagatelles laborieuses qui exigent une bonne humeur constante (bonne humeur nécessaire même pour traiter des sujets tristes), une excitation bizarre qui a besoin de spectacles, de foules, de musique, de réverbères même, voilà ce que j'ai voulu faire ! Je n'en suis qu'à soixante, et je ne peux plus aller. J'ai besoin de ce fameux bain de multitude dont l'incorrection vous avait justement choqué.
}

Cad. Trad., Florianópolis, v. 38, $\mathrm{n}^{0}$ esp. Baudelaire 150 anos, p. 54-69, ago-dez, 2018 
"Bagatelas laboriosas", "penetrantes e leves", segundo outra fórmula ambivalente usada por Baudelaire, anos mais tarde, em carta destinada ao mesmo Sainte-Beuve, os poemas em prosa foram concebidos para estremecer a tradicional hierarquia dos gêneros literários, colocando em xeque o espaço social, o registro de linguagem e a própria função da poesia lírica. Dessa forma, a "segunda revolução baudelairiana", se aceitamos a leitura de Barbara Johnson (1979), não poderia se realizar sem a modificação dos parâmetros de recepção, o que implica em uma revisão crítica do conceito de poesia e de suas relações de fronteira com a prosa, o que a Teoria da Literatura só começaria a empreender, de maneira sistemática, muitas décadas após a publicação dos Petits poèmes en prose. Essa modificação dos parâmetros de recepção exigida pelo caráter revolucionário do projeto baudelairiano de passagem para a prosa incide diretamente, claro, sobre a maneira como aqueles poemas são traduzidos mundo a fora. Parece inegável que o contexto de recepção tradutória de uma obra que "marca um começo absoluto" na história literária precisa ser acompanhada de uma renovação teórico-crítica que abrange todo o sistema literário no qual se insere o tradutor. Veremos que essa necessidade explica, em grande medida, a história das traduções brasileiras de Le Spleen de Paris.

No Brasil, por muitos anos, também vigorou a mesma dificuldade em se reconhecer nos poemas em prosa uma experiência válida por si mesma. Na esteira da primeira recepção de Baudelaire entre nós, ainda no século XIX, as primeiras leituras do Spleen de Paris no Brasil também se deram sob o influxo de uma concepção estetizante de poesia, que atravessa a primeira metade do século para renascer na geração de 1945, deixando sua marca naquela que viria a se consolidar como a tradução integral mais conhecida dos poemas em prosa entre nós, feita por Aurélio Buarque de Holanda e publicada em livro em $1950^{2}$.

${ }^{2}$ Trata-se da segunda tradução integral do livro no Brasil. A primeira, de autoria de Paulo M. Oliveira (pseudônimo do jornalista Aristides Lobo), apareceu em 1937 publicada pela Editora Athena. Mais prosaica e próxima do português coloquial,

Cad. Trad., Florianópolis, v. 38, n $^{0}$ esp. Baudelaire 150 anos, p. 54-69, ago-dez, 2018 
Em artigo recente, dedicado à análise da tradução de Holanda, Marcelo Jacques de Moraes (2017) define os dois caminhos opostos seguidos pelos tradutores ao longo da história das traduções do Spleen de Paris. Na mesma linha dos primeiros tradutores dos poemas em verso, Holanda trabalha sempre "um tom acima do original", buscando aquilo que o crítico define como uma espécie de compensação poética para a trivialidade estilística da prosa baudelairiana. Em resumo, as análises e comparações empreendidas por Marcelo Jacques de Moraes demonstram que Os pequenos poemas em prosa de Aurélio Buarque de Holanda manifestam a mesma dificuldade ou resistência diante do prosaísmo e dos torneios coloquiais que Antonio Candido (2006) identificara nos primeiros baudelairianos brasileiros da década de 1870. É certo, contudo, que essa tradução iria se tornar uma referência diante da qual os tradutores subsequentes teriam que se posicionar, aderindo ou recusando o seu estilo acadêmico e rebuscado.

Le Spleen de Paris só ganharia uma terceira tradução brasileira trinta e oito anos depois da de Aurélio Buarque de Holanda. A partir das novas traduções que se seguem -seis no total - delineia-se a segunda via pela qual se enveredaram os tradutores brasileiros dos pequenos poemas em prosa, a via do coloquialismo e da informalidade. Tome-se como um exemplo entre vários possíveis o trecho inicial de Le Chien et le flacon, na tradução de Alessandro Zir publicada pela editora L\&PM em 2016: “- Que fofo, que amado, que lindo cãozinho; venha cá cheirar este excelente perfume com-

é significativo que essa tradução não tenha se tornado hegemônica como a de Aurélio, caracterizada pelo "rebuscamento" da linguagem e pela elevação do tom em relação ao original (Cf. MORAES, 2017, p. 273-288). Sobre a identidade e o trabalho de Paulo M. Oliveira, remeto o leitor ao artigo de Denise Bottman (2012) publicado na revista Traduzires, da UnB, em 2012. Agradeço aos colegas baudelairianos Gilles Abes, Ricardo Meireles e Ellen Antonelli pelas sugestões bibliográficas e pelo debate em torno das primeiras traduções dos poemas em prosa de Baudelaire realizado durante o Simpósio número 15 - "Baudelaire no Brasil: traduções, recepção poética e crítica" - no âmbito do XV Congresso Internacional da Abralic, que teve lugar na UERJ no princípio de agosto de 2017.

Cad. Trad., Florianópolis, v. 38, n $^{0}$ esp. Baudelaire 150 anos, p. 54-69, ago-dez, 2018 
prado na melhor botica da cidade" (BAUDELAIRE, 2016, p.29). As diferenças de tonalidade em relação às traduções mais poéticas saltam aos olhos, a começar pelo título; $O$ cachorro e o frasco, na tradução de Zir, e $O$ cão e o frasco, na tradução de Aurélio Buarque de Holanda e na de Dorothée de Bruchard. Para o trecho inicial do poema, Holanda oferece a seguinte tradução: “- Meu belo cão, meu cãozinho, meu querido totó, vem cá respirar um excelente perfume comprado no melhor perfumista da cidade". Mais próxima do texto em francês, ("- Mon beau chien, mon bon chien, mon cher toutou, approchez et venez respirer un excellent parfum acheté chez le meilleur parfumeur de la ville"), a versão de Holanda soa, contudo, mais formal e requintada, graças a expressões como "Meu belo cão", "meu querido totó" e "perfumista", que, para os ouvidos brasileiros, soam demasiado literárias, convencionais e distantes da fala cotidiana. Acrescente-se a isso a opção de Holanda em manter a segunda pessoa no tratamento que o poeta dá ao cão. Já Alessandro Zir, que traduz a segunda pessoa francesa pelo pronome de terceira pessoa "você", opta explicitamente por uma linguagem mais prosaica - beirando o patético, como no caso do adjetivo "fofo". Mais próximo do chão do real do que o "cão" de Holanda, o "cachorro" de Zir não vem "respirar", mas "cheirar" o perfume oferecido pelo poeta. Se, por um lado, a tradução de Holanda parece pecar pelo convencionalismo poético, recurso certamente utilizado como forma de compensar a despoetização realizada pela poesia em prosa baudelairiana, não me parece incorreto afirmar que a tradução de Zir peca pelo extremo oposto. A opção pelo pronome pessoal "você", por exemplo, esvazia o efeito de estranhamento cômico propiciado pelo tratamento formal dado pelo poeta a seu cão. O diálogo algo solene algo ridículo estabelecido com o animal, tratado o tempo todo na segunda pessoal do plural em francês, é, a meu ver, uma marca da ambivalência característica da prosa baudelairiana, que oferece ao tradutor o desafio de equilibrar as tendências opostas do esteticismo poético e da radicalização prosaica, a fim de alcançar a irredutibilidade do poema a interpretações fáceis e rígidas. Le Chien et le flacon tem

Cad. Trad., Florianópolis, v. 38, n $^{0}$ esp. Baudelaire 150 anos, p. 54-69, ago-dez, 2018 
sido interpretado como uma espécie de parti pris aristocrático de Baudelaire diante da estupidez estética de seu público, alegorizada pela insensibilidade olfativa de seu cão. Mas como não ver nele também uma postura autoirônica do poeta que conversa com um cachorro na segunda pessoa do plural e espera dele uma apreciação estética refinada à moda dos grandes diletantes da aristocracia artística - com os quais, nós sabemos, Baudelaire sempre manteve uma relação ambivalente, de adesão e desprezo? ${ }^{3}$

É preciso fazer outra breve digressão teórica para compreender o que está em jogo nessa disputa entre o poético e o prosaico, que subjaz os debates atuais sobre a tradução dos pequenos poemas em prosa de Baudelaire. Nos últimos anos, a teoria da poesia tem entendido a prosa não mais como um gênero ou como uma forma (em oposição ao verso) mas como um registro definido em função de sua maior proximidade com o chão do real. A ideia da prosa para alguns poetas e teóricos contemporâneos se liga a um movimento descendente, se não de queda, ao menos de aterrissagem, e a uma aproximação objetivante da realidade ${ }^{4}$. "A prosa não é um gênero nem o oposto da poesia. Ela é o ideal baixo da literatura, dizendo de outra forma, um horizonte, e lhe insufla um ritmo, uma política", escreve o poeta francês Pierre Alferi no ensaio Vers la prose (2014, p. 1). Redefinições modernas como essa apontam para uma incorporação da prosa como "questão da poesia", conforme a expressão de Marcos Siscar (2016), isto é, como um problema inerente ao discurso poético e não exatamente como o seu oposto. A prosa torna-se, assim, um elemento de tensão no seio da poesia, um dispositivo crítico, se quiserem, que reforça a dissonância do poético em relação ao real. Outro poeta-teórico francês contempo-

\footnotetext{
${ }^{3}$ Em seu livro Baudelaire poésie et violence, Jérôme Thélot (1993) apresenta uma leitura bastante rica desse poema, identificando nele justamente uma abertura para a crítica mordaz contra a figura do poeta sublime, aureolado, distante do público. ${ }^{4}$ Esse mesmo movimento de descida e aproximação do chão é reconhecido por Jean-Marie Gleize no conjunto de poemas em prosa de Baudelaire, que delineia um percurso que se inicia, de fato, nas nuvens de L'Étranger e termina entre os vira-latas imundos que passeiam pela cidade em Les Bons chiens.
}

Cad. Trad., Florianópolis, v. 38, $\mathrm{n}^{0}$ esp. Baudelaire 150 anos, p. 54-69, ago-dez, 2018 
râneo, Jean-Marie Gleize, evocando o poema em prosa de Baudelaire La Chambre double, fala sobre a

\begin{abstract}
necessidade da passagem da poesia, da fabricação harmoniosa, do deleite da 'suficiente claridade da harmonia' (como fala Baudelaire em seu poema Chambre double), para a prosa, para o partido das prosas, o caráter inelutável da perda de auréola, o abandono do 'sonho de volúpia', e a submissão ao 'golpe de picareta no estômago' e àquilo que ele revela, desnuda, da 'realidade': o 'horror' e a 'desolação' (retomo exatamente suas palavras), da 'implacável vida' (GLEIZE, 2007, p. 166, tradução minha) ${ }^{5}$
\end{abstract}

Para além das disputas partidárias entre adeptos da poesia e adeptos da prosa, as pesquisas recentes em Teoria Literária acerca dos limites do discurso poético e sua relação com o prosaico trouxeram à tona, mais uma vez, a importância central do projeto literário dos Petits poèmes en prose de Baudelaire para a compreensão da crise da poesia lírica e das revoluções poéticas que a sucedem ao longo do século XX. Como não poderia ser diferente, o retorno aos poemas em prosa de Le Spleen de Paris como momento primordial dessa renovação literária, lança novas luzes sobre a tradução dessa obra, propondo, ao mesmo tempo, novos desafios aos tradutores.

Motivado pela difícil missão de ensaiar uma união entre os dois modelos de tradução dos poemas em prosa de Baudelaire que predominaram no Brasil, aceitei o convite da pesquisadora Isadora Petry e da editora Edipro para propor uma nova tradução de $L e$ Spleen de Paris, com previsão de publicação para o final de 2017.

${ }^{5}$ la nécessité du passage de la poésie, de la fabrication harmonieuse, de la délectation à la "suffisante clarté de l'harmonie" (c'est ainsi que parle Baudelaire dans sa Chambre double) à la prose, au parti pris des proses, le caractère inéluctable du scénario de perte d'auréole, l'abandon du "rêve de volupté", et la soumission au "coup de pioche dans l'estomac" et à ce qu'il révèle, met à nu, de la "réalité" l' "horreur" et la "désolation" (je reprends exactement ses mots), de l' "implacable vie".

Cad. Trad., Florianópolis, v. 38, $\mathbf{n}^{0}$ esp. Baudelaire 150 anos, p. 54-69, ago-dez, 2018 
O norte do nosso trabalho, recém-concluído, foi o "horizonte da prosa", sobre o qual escreve Pierre Alferi, mediado, contudo, pela resistência da poesia, pelo movimento de retração poética que impede a vitória definitiva da prosa, na obra de um poeta que confessa "permanecer preso, talvez para sempre, na vala do ideal", como se lê em "Laquelle est la vraie ?".

Para o já citado parágrafo inicial de Le chien et le flacon, procuramos equilibrar o esforço de prosaização das traduções mais recentes e o emprego, em alguns momentos, de certos convencionalismos retorico-literários que assumem, em Baudelaire, função irônica. Dessa forma, optamos pela manutenção do tom de formalidade, traduzindo a segunda pessoal do plural francesa pela segunda do singular em português. Optamos também pela palavra "cão", a fim de manter uma certa aura de distinção que perpassa - não sem ironia - todo o poema. Achamos que o vocábulo "cachorro" banalizaria demasiadamente um poema que aposta, segundo nossa leitura, no efeito cômico do contraste entre a elegância afetada da voz poética e a obtusidade do interlocutor - mais próxima da neutralidade do "cão" que da trivialidade familiar do "cachorro". Também mantivemos o verbo "respirar", conforme a tradução de Aurélio Buarque de Holanda e mais próximo do francês, entendendo que o verbo "respirer", empregado por Baudelaire em detrimento, por exemplo, de "sentir" e "flairer", mais próximos do universo animal, também cumpre função irônica no poema, uma vez que contribui para uma sutil humanização do interlocutor. Quanto ao adjetivo "belo", empregado por Aurélio na tradução literal de "beau", optamos por não conservá-lo, julgando-o muito convencional para uma frase que expressa, apesar de tudo, uma proximidade afetiva entre o poeta e seu cão. Por fim, ao invés de "perfumista" e "botica", empregados respectivamente por Holanda e Zir, optamos por uma solução mais próxima da realidade brasileira atual, "perfumaria"; menos, contudo, por uma questão de contextualização histórico-cultural que pelo equilíbrio estilístico que o efeito familiar-prosaico do termo pode emprestar ao parágrafo como um todo. Nossa versão de $O$ Cão $e$ o frasco começa, 
portanto, da seguinte forma: “- Meu lindo cão, meu bom cãozinho, meu querido totó, aproxima-te e vem respirar um excelente perfume comprado na melhor perfumaria da cidade".

Outro problema de tradução diretamente relacionado à compreensão do projeto poético de Baudelaire sobre o qual nos detivemos atentamente diz respeito ao emprego particular que o poeta faz do lugar-comum em seus poemas em prosa. Duas vias contraditórias se delineiam na prática poética do autor de Le Spleen de Paris. Partindo da retomada de clichés colhidos por ele na língua do dia a dia ("la belle langue de notre siècle"), a primeira delas procura ressignificá-los, numa espécie de antecipação da proposta de Mallarmé, cuja poesia se proporia, anos mais tarde, a "dar um sentido mais puro às palavras da tribo" (MALLARMÉ, 1998, p. 38); percorrendo o sentido contrário, a segunda via foi definida pelo próprio Baudelaire no fragmento XIII de Fusée: "Créer un poncif, c'est le génie. Je dois créer un poncif" (BAUDELAIRE, 1975 , p. 662). Criar um lugar comum pressupõe uma contribuição ao léxico da língua, o acréscimo de uma expressão ou de um sentido que, por força da inserção do discurso poético na espaço comum/comunitário (lembremos que os poemas foram concebidos para a publicação na imprensa; em muitos casos, em jornais de grande circulação em Paris, como La Presse e Le Figaro), seriam incorporados ao uso cotidiano, à língua da rua. Neste último caso, destacam-se os usos sistemáticos de determinadas expressões compostas por vocábulos chave para a poética do Spleen de Paris, como "banho" e "explosão", para citar apenas dois. No poema Les Foules, por exemplo, Baudelaire fala do privilégio que só o poeta tem de tomar um "banho de multidão" (bain de multitude), expressão cuja "incorreção chocara Sainte-Beuve", conforme nos mostra a carta endereçada a ele em 4 de maio de 1865 já citada acima. A palavra "banho" aparece outras quatro vezes nos poemas em prosa de Baudelaire, formando as seguintes expressões: "bain de parresse" ["La Chambre Double"] (BAUDELAIRE, 1975, p. 280), "bain de ténèbres" ["À une heure du matin" e "Anywhere out of the world"] (BAUDELAIRE, 1975, p. 287 e p. 357) e "bain

Cad. Trad., Florianópolis, v. 38, n $^{0}$ esp. Baudelaire 150 anos, p. 54-69, ago-dez, 2018 
du soir" [Déjà] (BAUDELAIRE, 1975, p. 337). Além de compor o vasto conjunto de imagens aquáticas presente em Le Spleen de Paris, o vocábulo "banho", talvez em função de sua trivialidade, produz uma espécie de estranhamento semântico quando utilizado metaforicamente, conforme comprova a reação de Sainte-Beuve mencionada por Baudelaire em sua carta. Por tudo isso, acreditamos que a supressão desse termo, em qualquer um dos poemas supracitados, prejudica o efeito poético resultante da criação de um novo topos que se espalha ao longo da obra e cumpre função central para o entendimento de sua poética. Para ficar em um único poema, dois tradutores brasileiros optam suprimir o "banho" do poeta em "Les Foules". Na tradução de Leda Tenório lê-se "Não é dado a qualquer um mergulhar na multidão" (BAUDELAIRE, 1995, p. 41); e na de Oleg Almeida, "Mergulhar na multidão não é para qualquer um” (BAUDELAIRE, 2010, p. 39).

Na outra direção do raciocínio, temos a prática baudelairiana do reaproveitamento crítico do cliché. Pensemos, por exemplo, na expressão corrente "casser les vitres" (dizer tudo, sem cerimônia, sem eufemismos), que adquire "um poder performativo" quando empregada no poema "Le Mauvais vitrier", que conta a história do vidraceiro atacado pelo poeta e que tem sua mercadoria destruída por ele (Cf. LABARTHE, 2000, p. 138). Contudo, o caso mais interessante de ressignificação de clichés se dá no uso de expressões teológicas. "Chaos" e sua versão hebraica galicizada "tohu-bohu" são termos presentes em diversos textos de Baudelaire. Ambos entraram no léxico francês pela via do discurso bíblico e foram aos poucos se transformando em expressões correntes com o sentido figurado de desordem, mistura e confusão, que entra em uso definitivamente no final do século XVI. Uma das particularidades do uso que Baudelaire faz desses dois lugares-comuns, conforme nossa avaliação, é justamente a recuperação de seu antigo sentido religioso. Isso fica claro em uma das primeira aparições de "tohu-bohu" na pluma do poeta, neste trecho do artigo sobre Théodore de Bainville:

Cad. Trad., Florianópolis, v. 38, n $^{0}$ esp. Baudelaire 150 anos, p. 54-69, ago-dez, 2018 
Paris não era então aquilo que é hoje, um tohu-bohu, uma cafarnaum, uma Babel povoada de imbecis e de inúteis, pouco delicados em suas maneiras de matar o tempo, e absolutamente rebeldes aos prazeres literários (BAUDELAIRE, 1976, p. 162; tradução minha). ${ }^{6}$

A aproximação entre três clichés de origem bíblica - tohu-bohu, capharnaüm e Babel - tem como efeito o encontro da língua comum e a recuperação do sentido religioso de desordem, decadência, confusão e destruição. Não por acaso, "chaos" e "tohu-bohu" serão frequentemente utilizados pelo poeta na descrição da Paris moderna, que, como se sabe, ele considerava como símbolo de perda ontológica e de decadência estética e moral no mundo moderno. O termo "chaos" também flutua no interior da própria obra baudelairiana, desde o uso teológico tradicional nos poemas em verso "Châtiment de l'orgueil" e "De Profundis clamavi" até o emprego aparentemente retórico nos poemas em prosa "Perte d'auréole" e "Un plaisant". Neste último, o termo é acompanhado de "tohu-bohu" (corruptela francesa da expressão bíblica hebraica "Tôhu wâbohû") mais uma vez na descrição que o poeta apresenta da metrópole moderna:

C'était l'explosion du nouvel an : chaos de boue et de neige, traversé de mille carrosses, étincelant de joujoux et de bonbons, grouillant de cupidité et de désespoirs, délire officiel d'une grande ville fait pour troubler le cerveau du solitaire le plus fort. Au milieu de ce tohu-bohu et de ce vacarme, un âne trottait vivement, harcelé par un malotru armé d'un fouet (BAUDELAIRE, 1975, p. 279).

\footnotetext{
${ }^{6}$ Paris n'était pas alors ce qu'il est aujourd'hui, un tohu-bohu, un capharnaüm, une Babel peuplée d'imbéciles et d'inutiles, peut délicats sur les manières de tuer le temps, et absolument rebelles aux jouissances littéraires.
}

Cad. Trad., Florianópolis, v. 38, $n^{0}$ esp. Baudelaire 150 anos, p. 54-69, ago-dez, 2018 
Nenhuma das traduções brasileiras disponíveis até então mantém o par de clichés bíblicos. Acreditamos, contrariamente, que a referência teológica deve ser mantida a fim de ressaltar a dimensão religiosa da crítica baudelairiana à modernização urbana. Na ausência de um vocábulo em português que remeta diretamente ao signo hebraico, optamos por manter o termo francês e acrescentar nota explicativa. Os parágrafos iniciais de nossa tradução de Un plaisant ficaram, portanto, da seguinte maneira:

Era explosão do ano novo: caos de lama e de neve, atravessado por mil carroças, faiscando de doces e brinquedos, fervilhando de ganâncias e de desesperos, delírio oficial de uma grande cidade feito para transtornar o cérebro do mais forte solitário.

No meio desse tohu-bohu ${ }^{7}$ e dessa barulheira, um asno trotava vivamente, açoitado por um grosseirão armado de um chicote.

Diferentemente da ideia radical de passagem total para a prosa, que anima as discussões contemporâneas na França, Baudelaire

\footnotetext{
${ }^{7}$ Versão afrancesada da expressão bíblica hebraica tôhu wâbohû, que corresponde ao "caos", termo de origem grega (Xóos) que também aparece no poema. Baudelaire emprega a expressão "tohu-bohu" acompanhada de outros termos bíblicos, também neste trecho do ensaio sobre Théodore de Banville, de 1861: "Paris não era, naquela época, o que é hoje, um tohu-bohu, um cafarnaum, uma Babel povoada de imbecis e inúteis, pouco delicados em sua maneira de matar o tempo, e absolutamente rebeldes aos prazeres literários" (BAUDELAIRE, 1976, p. 162, tradução minha). Mesmo se tratando de uma expressão já incorporada pelo léxico da língua francesa no tempo de Baudelaire como sinônimo de desordem, confusão, balbúrdia, optamos por manter o significante "tohu-bohu" a fim de não enfraquecer a conotação teológica presente na descrição da cena. "Satânica e apocalíptica", a cidade moderna baudelairiana "desfaz a criação, a ordem divina, para fazer renascer a confusão, o caos primitivo, o tohu-bohu”, conforme a interpretação de Antoine Compagnon (2014, p. 174, tradução minha).
}

Cad. Trad., Florianópolis, v. 38, $n^{0}$ esp. Baudelaire 150 anos, p. 54-69, ago-dez, 2018 
vivenciou o movimento em direção à prosa como uma tensão insolúvel que coloca em xeque os próprios limites - formais, estilísticos, sociais e políticos - da poesia. Este parece ser, a julgar pela história das traduções de Le Spleen de Paris no Brasil, o maior desafio que essa obra propõe a seus tradutores, o de manter e potencializar essa tensão no que ela tem de irredutível tanto ao esteticismo poético quanto ao objetivismo prosaico. Assim, o caminho rumo à prosa deve ser entendido como um movimento sem fim, sem repouso, de reafirmação do paradoxo, da contradição e da crítica dos limites do poético, do verso e da prosa, como sugere o trocadilho contido no título francês do ensaio de Pierre Alferi, à revelia talvez do próprio autor, remetendo à tensão entre o verso - a poesia - e a prosa.

\section{Referências}

ALFERI, Pierre. Vers la prose. Remue - Littérature contemporaine sur Internet, Montreuil-sous-bois, s/d. Disponível em: <http://remue.net/cont/alferi1.html > . Acesso em: 20 out. 2016. Não paginado.

BAUDELAIRE, Charles. Correspondance. Texte établi, présenté et annoté par Claude Pichois avec la collaboration de Jean Ziegler. Paris: Gallimard, 1973a. v. 1. (Coll. Bibliothèque de la Pléiade.)

. Correspondance. Texte établi, présenté et annoté par Claude Pichois avec la collaboration de Jean Ziegler. Paris: Gallimard, 1973b. v. 2. (Coll. Bibliothèque de la Pléiade.)

. Euvres complètes. Texte établi, présenté et annoté par Claude Pichois. Paris: Gallimard, 1975. v. 1. (Coll. Bibliothèque de la Pléiade.) 
. Euvres complètes. Texte établi, présenté et annoté par Claude Pichois. Paris: Gallimard, 1976. v. 2. (Coll. Bibliothèque de la Pléiade.)

. O Spleen de Paris: Pequenos poemas em prosa. Tradução e apresentação de Leda Tenório da Motta. Rio de Janeiro: Imago, 1995.

. O Esplim de Paris: Pequenos poemas em prosa. Tradução de Oleg de Almeida. São Paulo: Martin Claret, 2010.

BERNARD, Suzanne. Le Poème en prose de Baudelaire à nos jours. Paris: Nizet, 1959.

BOTTMAN, Denise. Uma vinheta. Traduzires, Brasília, v. 1, n. 2, p. 31-36, 2012.

CANDIDO, Antonio. Os Primeiros baudelairianos. noite. 5. ed. Rio de Janeiro: Ouro sobre Azul, 2006. p. 23-38. A Educação pela

COMPAGNON, Antoine. Baudelaire l'irréductible. Paris: Flammarion, 2014.

GLEIZE, Jean-Marie. Les Chiens s'approchent, et s'éloignent. Alea, Rio de Janeiro, v. 9, n. 2, p. 165-175, jul.-dez. 2007.

JOHNSON, Barbara. Défigurations du langage poétique: la seconde révolution baudelairienne. Paris: Flammarion, 1979.

LABARTHE, Patrick. Patrick Labarthe commente les Petits poèmes en prose de Baudelaire. Paris: Gallimard, 2000.

MALLARMÉ, Stéphane. Euvres complètes. Édition présentée, établie et annotée par Bartrand Marchal. Paris: Gallimard, 1998. v. 1. (Coll. Bibliothèque de la Pléiade.)

MORAES, Marcelo Jacques de. Aurélio e os poemas em prosa de Baudelaire: notas sobre uma tradução rebuscada. tradução. Rio de Janeiro: 7Letras, 2017. p. . Sobre a forma, o poema e a 
SISCAR, Marcos. Figuras de prosa: a ideia da "prosa" como questão de poesia. SCRAMIM, Susana; SISCAR, Marcos; PUCHEU, Alberto. $O$ duplo estado da poesia: modernidade e contemporaneidade. São Paulo: Iluminuras, 2015. p. 29-40.

THÉLOT, Jérôme. Baudelaire poésie et violence. Paris : Gallimard, 1993.

Recebido em: $15 / 08 / 2018$

Aceito em: 17/10/2018 Publicado em dezembro de 2018

Eduardo Horta Nassif Veras. E-mail: eduardohnveras@gmail.com ORCID: https://orcid.org/0000-0003-4803-1482

Cad. Trad., Florianópolis, v. 38, $\mathrm{n}^{0}$ esp. Baudelaire 150 anos, p. 54-69, ago-dez, 2018 